\title{
O CICLO HIDROLÓGICO COMO CHAVE ANALÍTICA INTERPRETATIVA DE UM MATERIAL DIDÁTICO EM GEOLOGIA
}

\section{The water cycle as an interpretative analytical clue to analyse a didactic textbook of Geology}

\author{
José Roberto Serra Martins ${ }^{1}$ \\ Pedro Wagner Gonçalves ${ }^{2}$ \\ Celso Dal Ré Carneiro ${ }^{3}$
}

\begin{abstract}
Resumo: Desenvolveu-se modelo de análise da concepção geocientífica veiculada em livros didáticos de Ensino Superior, baseado no ciclo da água, sua dinâmica, fluxos e interações. O modelo forneceu bons resultados, ao ser aplicado ao livro "Challenge of the Natural Environment", de Knapp, Ross e McCrae, que descrevem diferentes categorias de riscos geológicos. No ensino de geociências é fundamental distinguir entre os objetos de investigação e de estudo. Os estudos geológicos buscam recompor o objeto de estudo da Geologia - o processo histórico-geológico - a partir das formas fixadas em rochas e materiais sólidos. O objeto de investigação é a parte acessível da Terra: a crosta, com sua ampla variedade de estruturas, composições, tramas e texturas de rochas. Ao se distinguir objeto de estudo e de investigação, avaliam-se objetivamente riscos ocasionados: (a) pelo desconhecimento dos fenômenos naturais ou (b) quando se desconsideram efeitos de atividades antrópicas sobre a natureza.

Palavras-chave: Ciclo hidrológico. Epistemologia. Geologia. Livro didático. Ensino de Ciências da Terra.

Abstract: This article analyses the textbook published 1991 "Challenge of the Natural Environment", written by Brian Knapp, Simon Ross and Duncan McCrae, adopting the water cycle as a dynamic background for the flows and interactions between the Earth spheres. The water cycle helps students to understand the difference between the subject matter and the investigation of Geology, a distinction which is fundamental for the teaching of Earth Sciences. Such approach helps to understand the way Geology has evolved as a science. The object of investigation is the crust, where a great diversity of structures, rock compositions, fabrics and textures exist. The subject matter is the historical-geological process reconstructed from naturally "fixed" forms. The step-by-step approach goes from the simplest to the most comprehensive concepts; it highlights the risks caused by: (a) an incomplete knowledge of natural processes or (b) absence of concern for effects of human activities on nature.
\end{abstract}

Keywords: Water cycle. Epistemology of Geology. Textbooks. Teaching of Earth Sciences.

${ }^{1}$ Graduado em Geografia e Química, mestre em Ensino e História de Ciências da Terra. Professor de Ensino Médio e Superior. Campinas, SP, Brasil.<serra65@uol.com.br>

${ }^{2}$ Graduado em Geologia, doutor em Filosofia. Docente, Departamento de Geociências Aplicadas ao Ensino, Instituto de Geociências, Universidade Estadual de Campinas (IGE/Unicamp). Campinas, SP, Brasil. <pedrog@ige.unicamp.br>

${ }^{3}$ Graduado em Geologia, livre docente nas áreas de Ciências da Terra e Comunicação em Geociências. Docente, Departamento de Geociências Aplicadas ao Ensino, IGE/Unicamp. Campinas, SP, Brasil.

<cedrec@ige.unicamp.br>

${ }^{1}$ Rua Votorantim, 100, apto. 94

Campinas, SP

13.073-090 
Martins, J. R. S.; Gonçalves, P. W.; Carneiro, C. D. R.

\section{Introdução}

Este estudo pretende trazer elementos que ajudem a compreender a concepção científica veiculada por livros didáticos de Ensino Superior. Diversos tipos de estratégia podem ser utilizados para analisar tais obras. Podemos fazer uso de recursos qualitativos, como p.ex. a avaliação descritiva da evolução de um tema em determinada obra, que nos possibilita compreender o caminho seguido pelos autores, ao desenvolverem o material, no intuito de explicarem determinado conceito-chave ou tema. Também podem ser adotados recursos quantitativos, por meio da mensuração do número de páginas, figuras, diagramas, gráficos e tabelas destinadas a explicar certo assunto, bem como sua interpretação.

Livros didáticos são aqueles cujo fim específico é a educação escolar formal. Gérard e Roegiers (1998) indicam tanto os passos que podem ser seguidos por avaliadores quanto aqueles que poderiam orientar autores de livros didáticos. Dentre os múltiplos aspectos descritos no texto, assinalamos um especialmente relevante no âmbito do ensino de Ciências: a concepção veiculada pelo material didático. Fracalanza e Megid Neto (2006) exemplificam como estudar livros didáticos de Ciências: sugerem metodologia que incorpora distintas dimensões para avaliar a qualidade dos livros didáticos, mas, de certo modo, afastam-se do problema dos erros conceituais presentes nas obras. Quílez (2009), a partir do exame de livros de Química para Ensino Superior, revela que: (a) há uso excessivo de representações matemáticas, em lugar da valorização dos conceitos em si; (b) muitos autores contribuem para formar ideias errôneas. Dessa forma, os livros dificultariam a aprendizagem, em lugar de facilitarem.

A relevância dos livros didáticos e sua influência educacional podem ser evidenciadas pelo grande número de investigações a respeito de sua produção e utilização. $\mathrm{Na}$ área de ensino de Ciências, encontramos significativa diversidade. Stylianidou, Ormerod e Ogborn (2002), Cobo Merino e Batanero (2004), Campanario (2003), González Rodríguez; García Barros, Martínez Losada (2003) tratam de aspectos específicos de comunicação. Silva e Martins (2009) apresentam estudo semântico para descrever a concepção de ciência veiculada por livros didáticos. A metodologia de ensino pode ser estudada por intermédio de livros didáticos (p. ex. PANDIELLA; CALBÍ; MACÊAS, 2003; GARCÍA BARROS; MARTINEZ LOSADA, 2003). Fracalanza (1993) e Megid Neto (1998) revelam distintos assuntos e abordagens nas pesquisas sobre livros didáticos. Megid Neto e Fracalanza (2003) exibem múltiplas dimensões de livros didáticos de Ciências. A História da Ciência também recebe atenção nas pesquisas sobre livros didáticos (p. ex. ASSIS; ZYLBERSTAJN, 2001; MUÑOZ BELLO; BERTOMEU SÁNCHEZ, 2003; GONÇALVES, 2005).

As pesquisas pioneiras de Amaral (1981) e Cunha (1986), para analisar livros didáticos de Ciências da Terra destinados ao Ensino Superior, seguiram caminho muito diferente. Privilegiaram a concepção de ciência e as teorias que são veiculadas pelos materiais didáticos. Particularmente Amaral (1981) sugere que esses livros de texto podem ser examinados por categorias ou dimensões que caracterizam o conhecimento geológico: objeto de estudo, método, campos de aplicação e História da Geologia. Gonçalves (2005) retomou as dimensões de Amaral (1981) e investigou como se pode identificar a História da Geologia em um livro didático de Ciências da Terra. Revelou que os autores podem atribuir maior ou menor importância à História da Ciência. A análise se apoiou na identificação de menções históricas no interior das obras didáticas e na apreciação de sua importância dentro do livro. 
Neste trabalho, esmiuçamos outro elemento de Amaral (1981). A aplicação do conceito de objeto de estudo a obras didáticas pode aclarar o desenvolvimento da perspectiva ambiental nelas presente. Nesse quadro, é preciso considerar a separação entre os conceitos de objeto de estudo e objeto de investigação, que constituem elementos fundamentais da Geologia como ciência. O texto de Knapp, Ross e McCrae (1991) servirá como exemplo para revelar de que modo o ciclo da água e suas implicações ambientais são tratados em livros didáticos de Ciências da Terra.

Esta pesquisa investigou como o ciclo da água é tratado em um livro didático de Ciências da Terra. Isso permite caracterizar a abordagem dada pelos autores para desenvolver materiais didáticos desse campo de conhecimento. $\mathrm{O}$ trabalho pretende, ainda, contribuir para construir descritores que possam ser usados, por pesquisadores do ensino de Ciências da Terra, para examinar livros didáticos para o nível superior. De fato, tentamos mostrar que a distinção metodológica entre objeto de estudo e de investigação pode ajudar a identificar a concepção de ciência presente em materiais didáticos.

Nosso propósito é examinar o livro 'Challenge of the natural environment', de Brian Knapp, Simon Ross e Duncan McCrae (1991), utilizando o ciclo hidrológico como chave interpretativa. O ciclo da água fundamenta o artigo, como veremos a seguir, na exata medida em que auxilia a compreender e a formar uma concepção apropriada de Ciência em geral e das Ciências da Terra em particular.

\section{Ciclo da água}

Entre os desafios que se apresentam aos autores de um material didático em Geologia, está o de mostrar aos leitores as ideias que funcionam como chaves apropriadas à interpretação geológica e que podem levar ao melhor entendimento dos ciclos naturais, bem como suas forças motrizes e fluxos de energia envolvidos.

Amplo conjunto de trabalhos discute dificuldades cognitivas envolvidas no entendimento do ciclo da água, bem como suas funções na formação científica e ambiental. Ao mesmo tempo, muitos argumentos são encontrados para valorizar o entendimento do ambiente. Lobato (2009), p.ex., extraiu, da legislação brasileira do Ensino Médio, justificativa para tratamento de temas ambientais em livros didáticos de Química. Os ciclos podem envolver: desde determinado elemento químico, como carbono $(\mathrm{C})$, lítio $(\mathrm{Li})$ ou nitrogênio $(\mathrm{N})$, os diversos tipos de rochas presentes na crosta terrestre ou, até mesmo, feições de grande porte, como montanhas e oceanos, ao tratar de temas como, p.ex., o ciclo tectônico. Em nosso caso, estamos atentos ao mais conhecido dos ciclos naturais, que diz respeito à substância de capital importância para a manutenção da vida no planeta: a água.

Ben-Zvi-Assaraf e Orion (2005) mostram que, de um lado, estudantes na faixa de 1617 anos de idade perguntados sobre o ciclo da água revelam que entendem partes do ciclo, compreendem vários processos hidrobiogeoquímicos, mas falta a percepção da dinâmica do ciclo, ou seja, a visão sistêmica.

Somente os aspectos acima apontados justificariam estudar o que os livros veiculam do tema ciclo da água. Acrescentamos, ainda, a importância da água para a Astrobiologia. Requeijo e Carneiro (2010, p. 39) lembram que o conceito de zona habitável - definida como 
a região ao redor de determinada estrela onde "as condições físicas favorecem a existência de água no estado líquido na superfície do planeta" - está vinculado à existência de água neste estado físico, no planeta considerado, e padrões de circulação.

Alunos em fase pré-vestibular, por meio das aulas e da leitura dos materiais didáticos disponíveis, são capazes de assimilar conceitos importantes, tais como: os estados de agregação, os fluxos de energia e matéria na natureza, a gênese e os regimes pluviométricos, o comportamento geral dos ciclos naturais e as consequências do desmatamento e da poluição. Entretanto, na maioria das vezes, a abordagem desses temas não permite vinculação direta dos mesmos ao cotidiano dos alunos. Muitas vezes, por serem tratados de forma estanque e não integrada, revelam-se novos dilemas. Os mesmos alunos, capazes de entender conceitos deveras complexos - como balanço hídrico, natureza das rochas presentes no subsolo e formação de horizontes de solo - não são aptos a contextualizá-los de forma sistêmica. São conteúdos de extrema atualidade contemporânea e essenciais para a plena formação de cidadãos (CARNEIRO; TOLEDO; ALMEIDA, 2004; CARNEIRO et al., 2008; CARNEIRO; SIGNORETTI, 2008; MARTINS, 2010).

Note-se que tal problema não é exclusivo dos alunos de Ensino Médio ou Superior no Brasil. Na Itália, a título de exemplo, os alunos de licenciatura devem apresentar, ao final do curso, uma tesi di laurea, que deve integrar e contextualizar os conhecimentos adquiridos ao longo das disciplinas cursadas na graduação (ECO, 1989). Tanto lá como cá, esse tipo de procedimento (integração e contextualização conceitual) ainda é considerado um árduo desafio por parte dos alunos.

$\mathrm{Na}$ tentativa de tornar os alunos aptos à contextualização dos conceitos por eles apreendidos, um caminho utilizado é dado pela aproximação do objeto de estudo ao cotidiano do aluno. Como exemplo de tal estratégia, citamos o artigo 'Chuvas e enchentes: inovação curricular para ensinar o ciclo da água' (RIBEIRO et al., 2007), o qual propunha a explicação do ciclo a alunos do Ensino Médio de escolas públicas do interior paulista, a partir de seus conhecimentos cotidianos.

\section{Concepções de ciência}

As normas estabelecidas nos EUA para melhoria do ensino-aprendizagem de ciências constituem os 'National Science Education Standards' (NATIONAL RESEARCH COUNCIL, 1996). Essa referência nacional sintetiza visão geral sobre ensino de ciências; abrange os mais diferentes níveis, desde as especificidades das práticas em sala de aula até a organização do sistema educativo geral (NATIONAL SCIENCE TEACHERS ASSOCIATION, 1998). Os standards partem da premissa de que a ciência é um processo ativo.

A riqueza do processo científico foi apreciada por Rufatto e Carneiro (2009), que assinalam ser a ciência um processo eminentemente humano:

A ciência é um projeto humano, seus fundamentos, métodos, procedimentos, técnicas, temas, problemas, hipóteses, testes, são criados por nós, seres humanos. Não se trata de algo natural, inalcançável pela capacidade humana de transformação e direcionamento. Em razão da inexistência de regras rígidas e da diversidade humana, o fazer ciência 
O ciclo hidrológico como chave analítica ...

se constituiu, como o debate da Filosofia da Ciência nas últimas décadas demonstrou, em algo muito rico e variado. (RUFATTO; CARNEIRO, 2009, p. 274)

Tal concepção de ciência baseia-se nas características gerais da Ciência, uma atividade racional que busca, continuamente, a verdade e a expansão do conhecimento. A ciência é guiada pela lei natural, devendo ser testável e explanatória, embora seja, ao mesmo tempo, falsificável. As conclusões obtidas pelos cientistas são tentativas, ou seja, não representam, necessariamente, a última palavra. A ciência é continuamente debatida e avaliada, por meio de testes que podem ou não fortalecer as interpretações dominantes em determinado estágio evolutivo da ciência.

Aproveitando o formidável ambiente de discussão proporcionado pelos que fazem ciência, os 'National Science Education Standards' (1998) definem como altamente desejável, no ensino-aprendizagem de ciências, que se estimule um grau de desafio intelectual capaz de despertar o interesse e a atenção dos estudantes: "Aprender ciência é algo que os alunos fazem, não algo que é feito por eles. As atividades 'hands-on', embora sejam essenciais, não são suficientes. Os alunos devem ter experiências bastante 'minds-on"' (NATIONAL SCIENCE TEACHERS ASSOCIATION, 1998, p. 2; tradução nossa).

Esses elementos contribuíram para selecionar o texto de Knapp, Ross e McCree (1991) dentre dezenas de livros didáticos de Ciências da Terra para Ensino Superior. A construção do argumento toma por base casos, notícias de jornal, relatórios e, a partir desses, desenvolve explicações teóricas. O ciclo da água pode ser pormenorizadamente acompanhado em cada nível de abordagem ambiental presente nesse livro. Assim, o ciclo da água pode ser considerado uma chave interpretativa, ou seja, trata-se de fundamento essencial para compreensão da concepção de ciência acima. O caminho metodológico foi especialmente adaptado às características da obra examinada.

\section{Procedimentos de análise}

Há muitos modos diferentes de examinar livros didáticos. A presente análise acha-se inspirada na investigação pioneira sobre livros didáticos de Ciências da Terra (AMARAL, 1981). Toma-se o capítulo como unidade de análise para examinar o conteúdo, o enfoque e a rede formada de nexos que são construídos dentro da obra. Do ponto de vista da estrutura do conhecimento geológico, isso remete ao exame do conceito de objeto de estudo.

\section{Objetos de investigação e de estudo da Geologia}

A distinção entre objeto de investigação e objeto de estudo da Geologia é extremamente relevante na presente argumentação. Potapova (2007) desenvolve observações terminológicas que estabelecem contornos nítidos para cada um desses conceitos.

Para caracterizar uma ciência, falamos de seu objeto e metodologia, querendo dizer o método de pesquisa mais geral específico a ela. $\mathrm{O}$ objeto de qualquer ciência compreende certos fenômenos do mundo 
material. Ele é inesgotável como a própria ciência. O conceito "objeto de uma ciência" deve ser distinto do conceito "objeto de investigação". A confusão entre os dois conceitos freqüentemente leva a malentendidos. Assim, ouve-se freqüentemente que o objeto da geologia é a crosta terrestre. $\mathrm{Na}$ verdade, entretanto, a crosta e sua superfície não são mais do que os principais e imediatos objetos de investigação geológica: quanto ao objeto da geologia, pode ser definido como o processo histórico-geológico. A tarefa da geologia é estudar a história da Terra como um todo e suas várias esferas, camadas ou estratos e o núcleo. Por mais notáveis que sejam as propriedades da crosta terrestre (elas garantem uma discussão separada), a crosta não é mais do que uma das camadas da Terra e seria metodologicamente bastante errado, como veremos mais tarde, e de fato impossível considerá-la em separado dos outros estratos e do núcleo, em separado do processo histórico geral de evolução de nosso planeta. (POTAPOVA, 2007, p. 86-87)

Outra referência essencial para análise de livro considera, pois, que o objeto de estudo da Geologia é o conjunto de processos temporais que ocorrem no planeta. Em outros termos, a Geologia se ocupa do estudo da história da Terra toda (POTAPOVA, 2007, versão original de 1968), compreendendo as várias esferas materiais, o que inclui camadas e estratos desde os mais superficiais até aquelas unidades mais profundas, situadas no núcleo interno terrestre. A autora assinala que o objeto de investigação corresponde à parte do mundo material sobre a qual nos debruçamos para obter informações. Assim, o objeto de investigação seria dado pelas formas refletidas, 'fixadas':

A geologia é a única das ciências naturais que estuda os processos naturais numa forma refletida, "fixada" (ossificada = ossified no original), conforme registrado nas estruturas geológicas; estuda, ainda, a composição, estrutura e textura das rochas locais, representadas por minerais e restos fossilíferos de organismos vegetais e animais, o homem e suas ferramentas. (POTAPOVA, 2007, p. 87 - tradução de Conrado Paschoale)

No caso da Geologia, o objeto de investigação é a crosta terrestre, com suas rochas e estruturas, ou seja, o local onde identificamos registros, produtos, formas fixadas (que Potapova denominou "ossificadas") de processos ocorridos no passado. Essa ideia será a chave interpretativa para examinar como aparece o ciclo da água no livro didático.

Dentro de cada capítulo (unidade de análise), investigou-se a importância relativa do ciclo da água. Tomou-se como referência a ideia de objeto de estudo, ou seja, o problema que desenvolve o capítulo é centrado no ciclo da água, em algum de seus subciclos ou em outro tema qualquer. Somente quando predominar, no capítulo, o tema ciclo da água ou seus subciclos, ele tornar-se-á alvo para identificar se há ênfase nos processos atuais ou se o ciclo da água foi examinado a partir de suas formas fixadas. Cada capítulo foi lido buscando interpretar o tratamento metodológico usado no desenvolvimento do ciclo da água. 


\section{Estrutura da obra}

O material didático em questão é dividido em cinco blocos temáticos, designados por algarismos romanos I, II, III, IV e V, perfazendo um total de 14 capítulos. Os blocos temáticos encontram-se na seguinte ordem: I. 'O desafio geológico' (p. 5-38); II. 'Vivendo com o tempo' (p. 39- 82); III. 'Gestão de paisagens’ (p. 83-164); IV. 'Gestão de recursos hídricos’ (p. 165214); V. 'Ecossistemas e a atividade humana' (p. 215-272). À medida que avançamos ao longo dos blocos temáticos, percebemos que a intervenção antrópica torna-se cada vez mais presente. Assim, ao avançar do primeiro ao último bloco, os autores assinalam que os processos naturais tornam-se cada vez mais passíveis de controle. Se prestarmos atenção à epígrafe do livro de autoria de Francis Bacon (1561-1626): "A natureza, para ser comandada, precisa ser obedecida", teremos visão clara do paradoxo identificado e proposto pelos autores.

Cada capítulo se inicia com uma charge alusiva ao tema (Figura 1) que, na sequência, é introduzido por meio de breve apresentação conceitual.

Após breve exposição sobre os fundamentos teóricos, necessários à compreensão da Geologia, cada tema é relacionado a um tipo de desastre natural; em todos aparecem materiais como mapas, representações, figuras e tabelas explicativas, que ponderam sobre as consequências dos desastres naturais, para, a seguir, mostrarem-se quais medidas preventivas ou corretivas podem ser tomadas de modo a evitar ou minimizar os efeitos de tais desastres.

Os autores propõem, a cada capítulo, um ou mais Estudos de Caso. Nesses, o leitor mobiliza os conceitos apreendidos visando à resolução de problemas reais ou prováveis. Por fim, a maioria dos capítulos traz um glossário de termos mais importantes do texto.

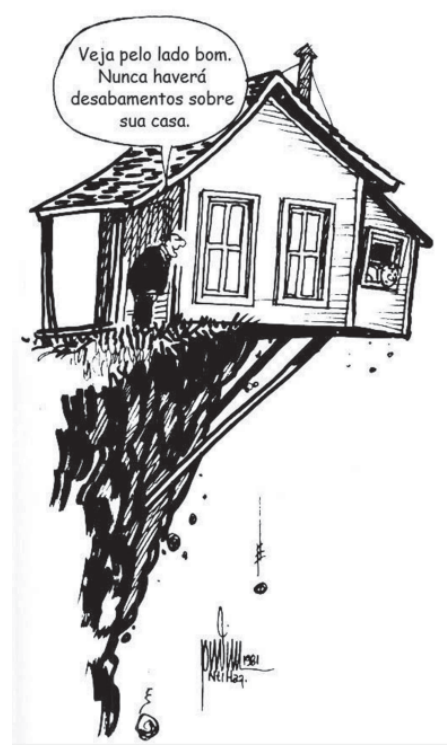

Figura 1. Charge de abertura do capítulo Encostas (Modificado de KNAPP; ROSS; McCRAE, 1991, p. 83). 
O bloco I é dividido em dois capítulos, denominados 'Placas tectônicas' (Capítulo 1) e 'Vulcanismo e riscos vulcânicos' (Capítulo 2). Os capítulos mostram a estrutura da Terra (crosta, manto e núcleo) e a divisão da crosta em placas tectônicas; também se revela como as atividades vulcânicas e sísmicas se encontram associadas a tais placas, sobretudo, pelo tipo de interação que ocorre entre elas.

Para mostrar que desastres naturais não são tão efêmeros quanto parecem, o material apresenta, na primeira página da introdução, um mapa do planeta, em projeção Mercator, no qual estão representadas as seguintes informações: (i) a distribuição global dos eventos sísmicos e vulcânicos; (ii) os limites das placas tectônicas; e (iii) os locais cuja densidade populacional é superior a $50 \mathrm{hab} . / \mathrm{km}^{2}$. É possível notar relevante concordância espaço-temporal entre (i), (ii) e (iii), o que corrobora a premissa dos autores (Figura 2).

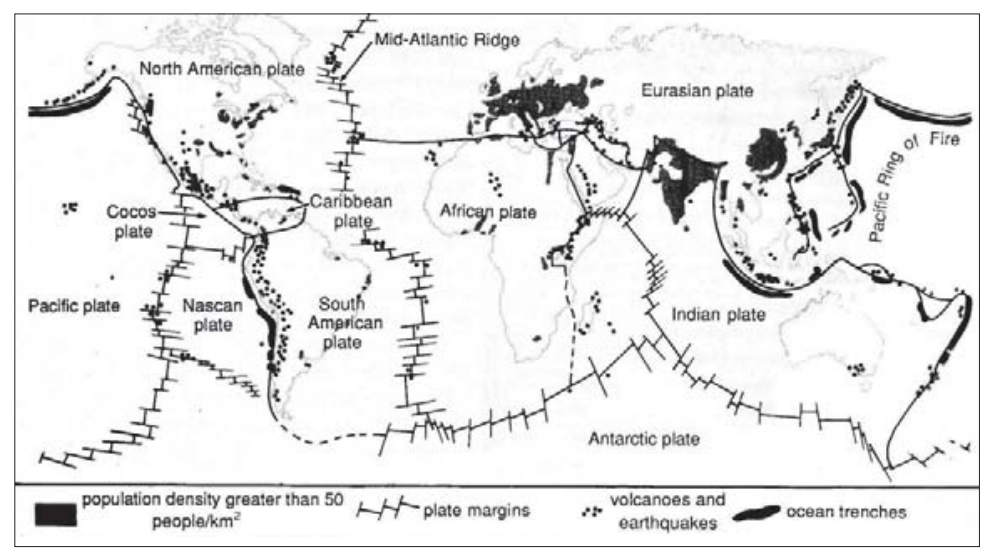

Figura 2. Mapa que introduz a premissa do livro-texto (Modificado de KNAPP; ROSS; McCRAE, 1991, p. 5).

Os autores definem, como principais metas do texto, mostrar:

[...] de que forma os processos naturais modelam o meio em que vivemos e como o conhecimento pode ser colocado em prática visando tanto o benefício da humanidade quanto a sobrevivência do ambiente natural. (KNAPP; ROSS; McCRAE, 1991, p. 4)

Atingir as metas propostas pelo texto constitui, em nossa opinião, o maior 'desafio' (challenge) da obra, cujo público-alvo, determinado pelos autores, vai desde estudantes de geologia até magistrados e administradores que se interessem pelo assunto.

Ao tratar dos abalos sísmicos, o material didático assinala que, em locais onde o substrato está inconsolidado, ocorre maior amplitude relativa das ondas de choque, sendo os danos materiais de grande monta; no caso de substrato rochoso, os danos são muito menores, uma vez que a solidez do terreno conduz a menor amplitude das ondas em questão, em 
virtude de os materiais envolvidos sofrerem menores oscilações devido à aceleração causada pela passagem das ondas sísmicas, tal como mostrado na Figura 3.

O livro nos mostra que evitar tal fenômeno é, por enquanto, impensável. Contudo, é sempre importante instigar a reflexão por meio de atividades que levem à análise dos fatos e à minimização das consequências do desastre natural.

O bloco II, também composto por dois capítulos, 'Clima global' e 'As pessoas e o clima', é dedicado à compreensão dos fenômenos naturais relativos ao clima e aos desastres causados pelo excesso de água ou pela falta dela. Para explicar como o excesso ou a falta desse recurso resulta de sua distribuição no tempo e no espaço, do que decorrem a maior previsibilidade e eventual controle do fenômeno. Nesse bloco, conceitos como a energia solar e sua distribuição, a circulação atmosférica e o ciclo da água são tratados de forma integrada; desse modo, pode-se obter um panorama sistêmico capaz de levar à compreensão: da posição geográfica das zonas de alta e baixa pressão (e suas variações temporais e espaciais), da existência das células de Hadley, da formação das nuvens, chegando à explanação sobre o padrão de circulação global e sobre o clima. Além disso, o bloco aborda temas como El Niño, monções (Figura 4), tufões, ciclones, furacões e suas consequências para o ambiente natural e para as pessoas que vivem nas áreas por eles atingidas. Por fim, o material propõe discussão sobre a possibilidade de ocorrência de variações climáticas por motivos antrópicos e quais as consequências da variação do clima para os habitantes de uma dada região, de um país ou, mesmo, de nosso planeta.

No bloco III, composto por quatro capítulos: 'Encostas', 'Costas', 'Ambientes frios' e 'Desertos', nota-se que é ainda maior a intervenção do homem sobre o ambiente, ideia evidenciada pelo sugestivo título desse bloco - Gerenciando relevos. Apesar de certos fenômenos naturais não serem previsíveis, as inúmeras intervenções possíveis sobre o meio podem minimizar as consequências dos desastres naturais associados ao relevo.

Começando pelos fatores envolvidos da formação de encostas, o material propõe que as encostas sejam pensadas como um sistema no qual as entradas são a chuva e a rocha

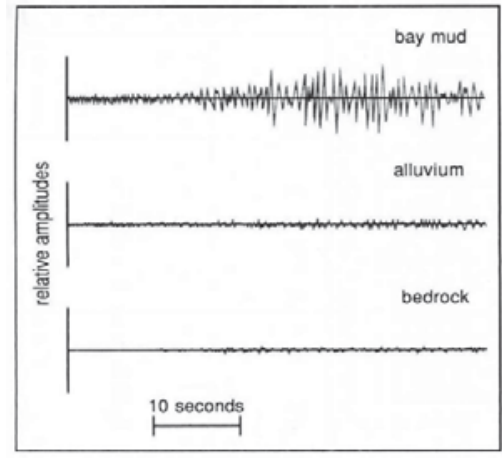

Figura 3. Amplitudes das ondas de choque em diferentes tipos de substrato (Modif. de KNAPP; ROSS; McCRAE, 1991, p. 10).

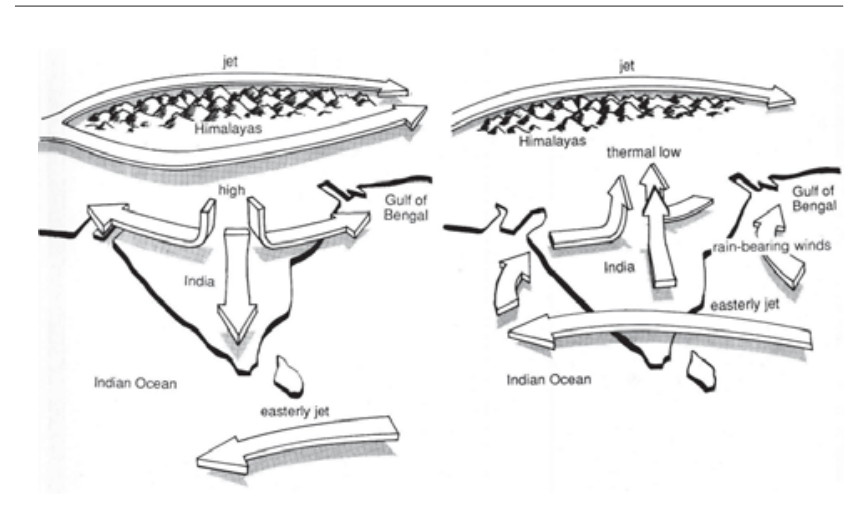

Figura 4. A variação sazonal na circulação e o fenômeno das monções (Modif. de KNAPP; ROSS; McCRAE, 1991, p. 49).

373 
intemperizada; processos como desmoronamentos, deslizamentos e fluxos têm lugar e as saídas ou produtos são o solo e a água.

Com base em tal análise, a encosta pode ser entendida como um sistema que envolve movimento progressivo de matéria e energia e que sofre forte influência dos fluxos de água e das condições atmosféricas. Tal raciocínio pode ser estendido ao transporte de sedimentos e ao estudo das costas e até ampliado, se levarmos em consideração a interação das ondas com a porção da litosfera dada pelo terraço continental e que leva ao delineamento do litoral. Note-se a importância relativa da água em estado líquido, no que tange a cada um dos processos citados.

É curioso notar que as transformações que observamos no meio natural não são devidas apenas a excesso de água. Quando em uma região há falta dessa, devido a baixos índices pluviométricos - ou a uma distribuição de chuvas ao longo do ano demasiadamente desigual - as mudanças podem ser promovidas pelo deslocamento rápido de partículas sólidas (na forma de tempestade de areia, p. ex.) ou pelo avanço de dunas, as quais podem causar: (a) destruição de moradias; (b) soterramento de áreas próprias à agricultura e canais de irrigação (Figura 5) e (c) fenômenos de assoreamento dos corpos d'água. A tudo isso, some-se o fato de a ação antrópica contribuir para o processo de desertificação, observado nos mais diferentes locais do globo.

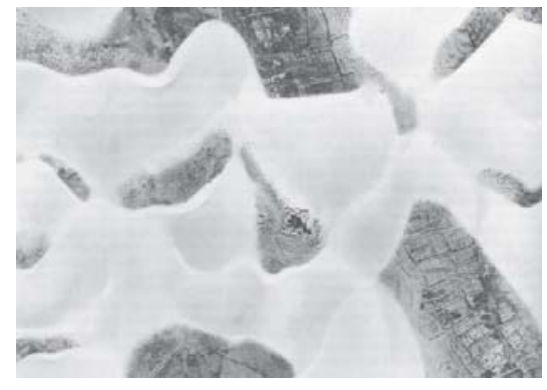

Figura 5. Dunas soterrando campos agricultáveis e canais de irrigação (Al-Hofuf - Arábia Saudita) (Modificado de KNAPP; ROSS; McCRAE, 1991, p. 160).

No bloco IV, composto por três capítulos, 'Recursos hídricos', 'Gestão de bacia hidrográfica' e 'Engenharia de canais fluviais', podemos perceber que a ação antrópica está ainda mais presente, sendo capaz de provocar grandes transformações no ambiente.

O bloco temático em questão inicia-se com uma rápida revisão de conceitos, sendo mais relevantes o ciclo hidrológico (Figura 6) e o balanço hídrico; o funcionamento deste último se faz em escalas desde macro ao micro. Discorrendo sobre problemas ocasionados pela explotação de água, o livro mostra não apenas como se dá a ação do homem sobre os recursos, mas também como podem ser instituídas formas de intervenção que minimizem tais problemas.

No mesmo bloco, apresentam-se os cursos d'água como responsáveis por modelar a paisagem e, em discussão mais aprofundada, como meios de transporte de sedimentos, além 


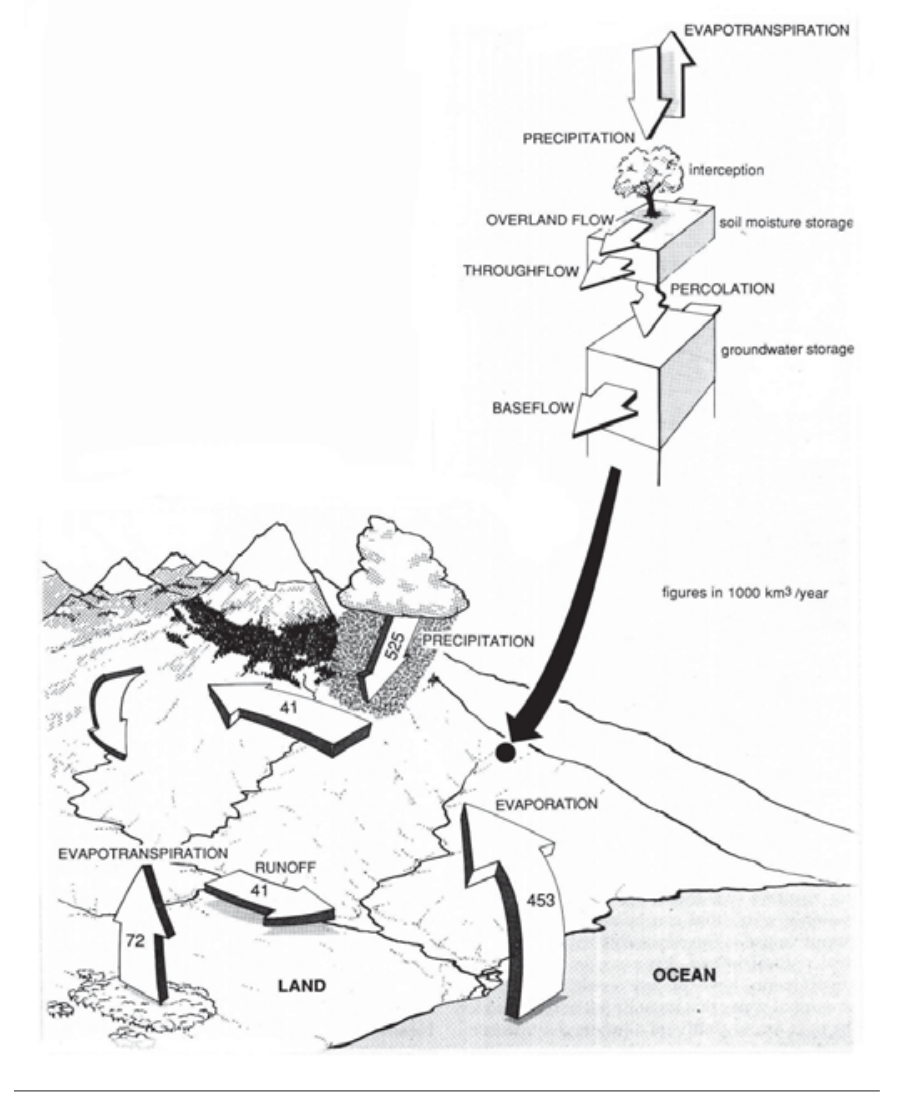

Figura 6. O ciclo da água em sua dinâmica e fluxos (Modificado de KNAPP; ROSS; McCRAE, 1991, p. 167).

de seus usos sociais, tais como: transporte de mercadorias, fonte de potencial hidrelétrico e, mesmo, como local de lazer e turismo.

Ao analisarem as bacias hidrográficas, os autores contrapõem os fatores do relevo, do uso e ocupação do solo e dos fluxos pluviométricos sazonais na tentativa de explicarem os regimes dos rios, e, assim, mostrarem os principais motivos que podem ocasionar enchentes em áreas urbanas e rurais.

Concluindo esse bloco, os autores mostram como ocorrem as mudanças graduais dos cursos dos rios que meandram pelas planícies, revelando não só o aparecimento de lagos marginais, bem como a formação dos bancos de areia em suas margens e os padrões de escoamento. Mostram, ainda, como se dá a construção de canais e sua tipologia, bem como discutem as consequências provenientes de tais intervenções.

O bloco V, que encerra a obra, é composto por três capítulos: 'Ecossistemas', 'O desafio do uso dos solos' e 'A gestão dos solos e o futuro'. Os capítulos dão sequência aos anteriores e culminam com a inclusão da ação antrópica como fator influente na determinação do ambiente. 
Tal bloco inicia com a apresentação do funcionamento de um ecossistema e de conceitos ecológicos muito importantes, tais como: teias alimentares, reciclagem de nutrientes, formação de húmus e produtividade primária líquida; revela ainda como se dão as relações ecológicas e quais os tipos de controle que são exercidos. Encerra-se com a análise dos impactos causados pela derrubada de florestas tropicais e como é possível o desenvolvimento sustentável destas; indaga sobre qual a melhor alternativa às florestas: Conservação ou Manejo?

O bloco V questiona o uso e a ocupação dos solos, levando a termo a discussão sobre fatores naturais responsáveis pela formação dos solos e formas pelas quais a ação antrópica exerce papel decisivo no processo. Conceitua os principais problemas enfrentados por quem faz uso do solo como substrato; discute, brevemente, acidez dos solos, e sugere maior planejamento no que tange à utilização.

O material encerra-se com a apresentação dos problemas relativos à erosão dos solos, formação de boçorocas (ou voçorocas), retornando ao assunto da desertificação e apresentando medidas que vêm sendo tomadas para conservação dos solos em alguns locais do planeta, citando as peculiaridades de cada uma.

Nos capítulos 1 e 2 praticamente não há referência à dinâmica da água. $\mathrm{O}$ tratamento do ciclo da água no décimo segundo capítulo é periférico porque a água limita-se a ficar implícita aos fenômenos ecológicos e às mudanças que ocorrem nos ambientes devido às atividades humanas. Os dois últimos capítulos dedicados ao solo tratam de sua formação, seu uso presente e futuro, sobretudo para a agricultura; neles não se enfatizam os caminhos da água.

Nos demais capítulos, a água, seus movimentos e suas transformações ocupam papel predominante ou, pelo menos, muito importante dentro de cada capítulo. Em item separado, explicitamos como o ciclo da água é tratado na obra.

\section{O ciclo da água na obra de Knapp, Ross e McCrae}

O terceiro capítulo, dedicado ao clima, expõe variáveis do equilíbrio radiante, características dos mecanismos atmosféricos e do ciclo da água. Valoriza os extremos climáticos (El Niño e furacões), bem como explica os padrões latitudinais de clima. Apresenta a poluição atmosférica e a distribuição de poluentes por meio dos ventos. Todos os processos são tratados no presente. Padrões e regularidades atuais servem para prever onde os fenômenos devem acontecer e quais são as precauções que população e autoridades devem tomar. Não inclui registro de climas do passado. Dessa maneira, o objeto de estudo circunscreve-se ao ciclo da água sem a dimensão temporal.

O quarto capítulo trata de mudança climática. Explica as variáveis naturais que modificaram o clima do passado. Inclui os fatores antrópicos que podem mudar o clima em escala local e global. O tempo envolvido nesses processos é relativamente restrito porque as variáveis listadas atuam em pequenos intervalos de tempo (dezenas a milhares de anos). Dentro desse intervalo de tempo, os autores tratam de marcas deixadas pelos climas nos limites do registro histórico, ou seja, o ciclo da água recebe tratamento temporal, embora não envolva o tempo profundo.

O quinto capítulo explica a dinâmica dos escorregamentos de encostas e insere o funcionamento do ciclo da água como parte do mecanismo envolvido no fenômeno, por meio do clima. A ênfase do texto é para o processo e, dessa maneira, o ciclo da água é parte da dinâmica, mas não é uma variável; o argumento não considera registros deixados pelo fenô- 
meno no passado. O sexto capítulo trata dos fenômenos costeiros, com especial atenção à formação de ondas, transporte de sedimentos e problemas ambientais (erosão, poluição). $O$ funcionamento atual do ciclo da água em seu subciclo de correntes costeiras ocupa o papel principal no texto. A abordagem, portanto, é limitada ao presente.

O sétimo capítulo enfatiza a dinâmica de formação dos ambientes periglaciais e os acidentes típicos de geleiras alpinas. O subciclo da água sólida ocupa papel central no texto, mas não há qualquer referência ao registro no passado.

A alteração do estado físico da água, devido a fatores como altitude ou latitude, introduz novas variáveis que devem ser levadas em consideração por aqueles que desejam estudar Geologia. Não é por estar em estado sólido que a água deixará de ser um agente atuante sobre o meio. Assim, o material didático dedica um capítulo inteiro à explicação das transformações causadas pelo gelo (seja sob a forma de neve, granizo ou geleira) ao deslocarse dinamicamente pelo relevo - cuja composição também pode contribuir para tais mudanças.

O oitavo capítulo trata da dinâmica de formação dos ambientes desérticos e sua ocupação predominantemente urbana. A falta de água e as tempestades que afetam as cidades vizinhas a zonas desérticas são aspectos que recebem especial atenção. $O$ ciclo da água é tratado ao esmiuçar o sistema climático que conduz à formação dos desertos e como recurso hídrico. Todo o estudo é limitado às condições do presente.

O capítulo nove inclui subitem, cujo título é 'O ciclo da água', que é explicado como balanço hídrico entre reservatórios terrestres. Trata, ainda, da distribuição regional da água na superfície terrestre e seus múltiplos usos, ou seja, trata da água como recurso (recurso hídrico). É estritamente a ideia funcional de ciclo da água, ou seja, são as condições do recurso hídrico no presente.

O décimo capítulo explica o funcionamento dos rios. Nesse funcionamento há a enchente e as formas de gestão de bacia hidrográfica. Há forte analogia na construção do argumento com o nono capítulo, em ambos o ciclo da água é eminentemente um fenômeno utilitário e estudado somente na perspectiva do presente. O capítulo 11 praticamente complementa o décimo, pois se restringe aos efeitos das mudanças antrópicas feitas nos rios, ou seja, completa a ideia de gestão de bacia hidrográfica.

\section{Discussão}

O estudo do tratamento dado ao ciclo da água revelou que o texto de Knapp, Ross e McCrae (1991) não toma o Tempo Geológico como eixo central para se compreenderem os fenômenos terrestres. O tratamento do ciclo da água e seus subciclos é sistêmico. Contribui para compreender a dinâmica atual do planeta, mas não recorre aos registros fixados na crosta terrestre para compreender o futuro curso de desenvolvimento do planeta.

Amaral (1981) havia reconstruído tendências de conteúdo e enfoque dos livros didáticos de Ciências da Terra. Tomando como base essa orientação, a obra estudada seria um híbrido de duas tendências: Geologia Ambiental e Geociências. A Geologia Ambiental se caracteriza, segundo Amaral (1981), pela pouca ênfase a assuntos tradicionais da Geologia (minerais, rochas, ciclo das rochas etc.), organiza o conteúdo em duas ideias centrais: fenômenos naturais que são destrutivos para a humanidade (terremotos, vulcões, escorregamentos etc.) e efeitos nocivos de interações provocadas pela sociedade (poluição, esgotamento de 
recursos naturais, crescimento demográfico etc.). O mesmo autor mostra que os livros de texto de Geociências ultrapassam os temas tradicionais da Geologia (minerais, rochas, processos endógenos e exógenos) e incluem ênfase no espaço extraterrestre, bem como nas dinâmicas da atmosfera e hidrosfera.

A maior preocupação dos autores é mostrar o ciclo hidrológico a partir de um ponto de vista sistêmico, de tal forma que:

- Fique claro ao estudante que a compreensão dos recursos hídricos de um dado local só é possível quando se conhecem o balanço hídrico e o ciclo hidrológico, bem como as variáveis que os afetam, direta ou indiretamente.

- A água apareça como parte integrante da chamada hidrosfera, mas também como agente de interação com as demais (litosfera, atmosfera e biosfera).

- Os fluxos de matéria sejam explicitados visualmente por setas que indiquem o sentido do fluxo, bem como a vazão da água, em milhares de quilômetros cúbicos por ano $\left(1.000 \mathrm{~km}^{3} /\right.$ ano, no original).

A quantidade de água precipitada (sob forma de chuva, neve, granizo etc.) é ilustrada como sendo a soma da parcela de água evaporada diretamente da hidrosfera e da parcela de água que deixa a biosfera por evapotranspiração (Figura 6). Podemos notar que o fluxo de água que sofre evaporação $\left(=453.000 \mathrm{~km}^{3} /\right.$ ano $)$ supera em seis vezes aquele que sofre evapotranspiração $\left(=72.000 \mathrm{~km}^{3} /\right.$ ano). Cabe observar, contudo, que esse valor é pequeno se comparado ao volume total de água dos oceanos (cerca de 1.348.000.000 $\mathrm{km}^{3}$ ) (CMIO, 1999, p. 164). Recordando-se que o nome tempo de residência médio é dado ao tempo que seria necessário, em média, para que todo o conteúdo de água do oceano passasse por todas as etapas do ciclo hidrológico, retornando ao mesmo, os dados acima resultariam em, aproximadamente, um tempo de residência médio de três mil anos nos oceanos.

Nos Estudos de Caso em que a água se faz presente, a substância é reiteradamente apresentada como parte integrante, e até fundamental, de um sistema. Uma série de dados consta dos Estudos de Caso com o objetivo de despertar, no estudante/leitor, interesse pela pesquisa dos temas e princípios propostos, além de levá-lo a perceber quais as atitudes a serem tomadas no que tange à resolução de futuros problemas envolvendo recursos hídricos e que são, na maioria das vezes, causados pela ação antrópica. Outro dado interessante sobre o material de análise é a quantidade de explicações sobre ciclo hidrológico feitas por meio de gráficos, gravuras, tabelas e esquemas, tal como observamos no esquema simplificado que ilustra a interação entre pessoas e recursos hídricos (Figura 7). Nesse caso, o balanço hídrico é fundamental para compreensão do direcionamento dos fluxos e problemas causados pela má administração desses recursos.

A opção de Knapp, Ross e McCrae (1991) foi atribuir proeminência ao ciclo da água sobre os demais temas de Ciências da Terra. Tópicos tradicionais acham-se ausentes na obra estudada (p. ex.: minerais e rochas). Os fenômenos relacionados à água ora são limitantes ou destruidores para as atividades sociais, econômicas e culturais, ou seja, há grande ênfase ao risco geológico. Atividades econômicas e sociais produzem mudanças no ciclo da água que geram prejuízos à humanidade (Figura 7). 


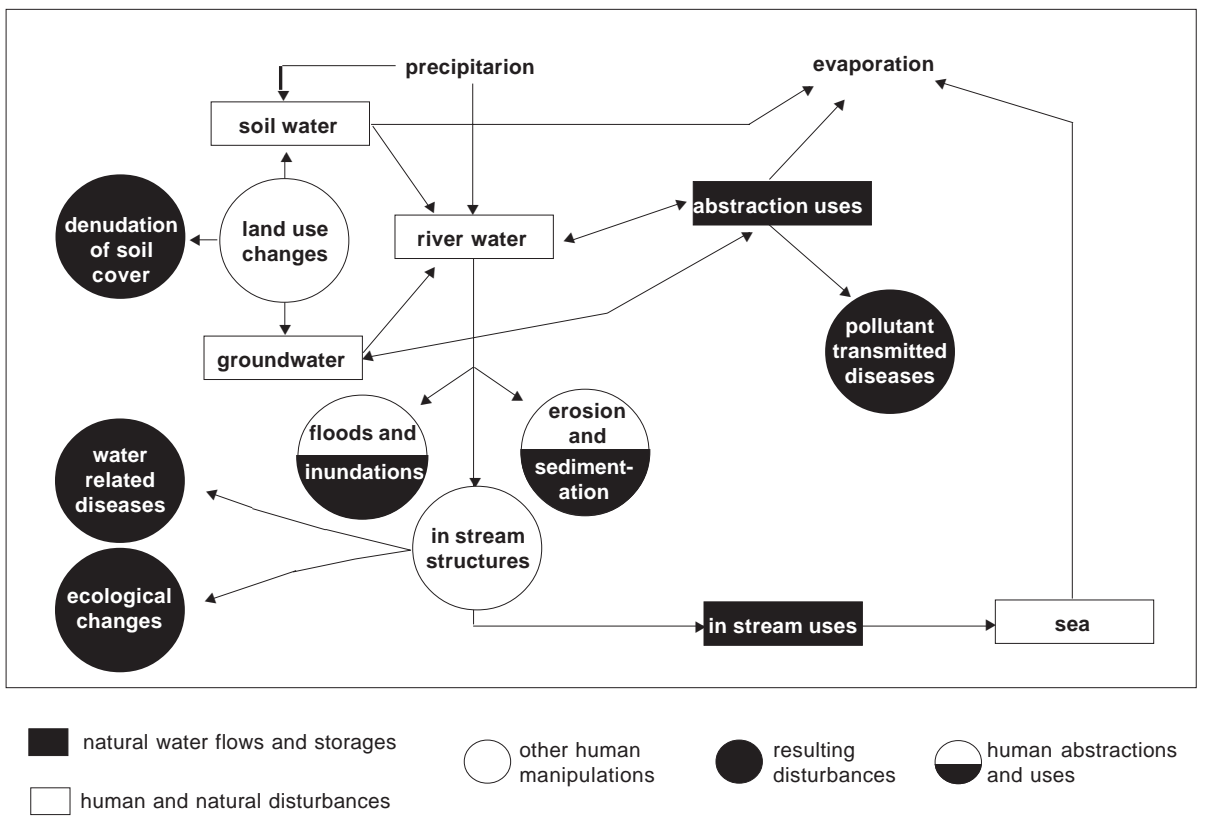

Figura 7. A ação antrópica sobre o ciclo hidrológico (Modif. de KNAPP; ROSS; McCRAE, 1991, p. 168).

\section{Conclusões}

O livro didático 'Challenge of the natural environment' foi analisado sob a perspectiva do ciclo da água. Percebemos que a substância, presente na maioria dos capítulos, atua direta ou indiretamente nos processos geológicos apresentados. A dinâmica da água exerce grande influência no relevo e na morfologia da paisagem, porque atua como: (a) um dos principais responsáveis pelo intemperismo químico; (b) agente indireto no intemperismo físico e biológico; (c) agente de transporte de massa, ou (d) meio polar presente nos processos de dissolução de outras substâncias. Tais influências ocorrem nas diversas escalas do clima em uma dada região e interferem até mesmo, por que não dizer, sobre a possibilidade de vida em dado local.

A análise do livro em apreço levou-nos a perceber que a escolha do caminho a ser seguido para a apresentação dos temas é, sobretudo, política, apesar de os temas seguirem lógica que respeita critérios técnicos estabelecidos pela própria ciência. $\mathrm{Na}$ Geologia, os conceitos atuais incluem-se em um 'núcleo duro' (ideológico) ou paradigma; desse modo, para estudarmos o conceito de ciclo em geologia, devemos ter clareza sobre qual é o 'objeto de estudo' de tal ciência, distiguindo-o de seu 'objeto de investigação'.

Em Geologia, é fundamental a separação entre objeto de estudo e de investigação, mas isto nem sempre é devidamente valorizado e reconhecido. Basicamente, todo estudo geológico, realizado a partir das formas refletidas, fixadas, ou 'ossificadas' nas rochas e outros materiais sólidos do planeta, nos traz informações e dados essenciais para recomposição de 
processos do passado terrestre e contribui para prever fenômenos futuros. Sabemos que a crosta terrestre, nosso objeto de investigação e parte do planeta, à qual podemos ter acesso direto, apresenta extrema variedade de estruturas geológicas, composição, trama e texturas de rochas. Tal abordagem ajuda a entender como se estabelece a relação íntima entre objetos de estudo e de investigação e como tal entrelaçamento possibilita o desenvolvimento da Geologia. O exame do ciclo da água pode tornar mais claras as relações que buscamos ao estudarmos os processos naturais e seu encadeamento na história evolutiva da Terra, incorporando o homem como agente geológico.

A premissa básica que orientou o livro é a de que as pessoas tomam consciência da natureza quando "despertadas" para processos a ela relacionados ou por ocasião de desastres naturais que ocorrem à sua volta. O desenvolvimento do ciclo da água enfatiza os riscos que a sociedade humana sofre ao desconhecer os fenômenos naturais ou ao desconsiderar os efeitos de atividades antrópicas sobre a natureza. Trata-se de perspectiva essencialmente utilitária da natureza.

\section{Agradecimentos}

Os autores agradecem ao Sr. Rodrigo César Teixeira de Gouvêa, estudante do curso de Geologia da Unicamp, pelo apoio na edição das ilustrações.

\section{Referências}

AMARAL, I. A. O conteúdo e o enfoque dos livros de geologia introdutória. 1981. 259f. Dissertação (Mestrado em Geologia Geral e de Aplicação) - Instituto de Geociências, Universidade de São Paulo, São Paulo, 1981.

ASSIS, A. K. T.; ZYLBERSZTAJN, A. The influence of Ernst Mach in the teaching of mechanics. Science \& Education, Sidney, v. 10, n. 1, p. 137-144, 2001.

BEN-ZVI-ASSARAF, O.; ORION, N. Development of system thinking skills in the context of earth system education. Journal of Research in Science Teaching, Maryland, v. 42 , n. 5 , p. $518-560,2005$.

CAMPANARIO, J. M. De la necesidad, virtud: cómo aprovechar los errores y las imprecisiones de los libros de texto para enseñar física. Enseñanza de las Ciencias, Barcelona, v. 21, n. 1, p. 161-172, 2003.

CARNEIRO, C. D. R.; SIGNORETTI, V. V. A carência de conteúdos de geociências no currículo básico comum de Geografia do Ensino Fundamental em Minas Gerais.

Geografia, Rio Claro, v. 33, n. 3, p. 467-484, 2008.

CARNEIRO, C. D. R.; TOLEDO, M. C. M.; ALMEIDA, F. F. M. Dez motivos para a inclusão de temas de Geologia na educação básica. Revista Brasileira de Geociências, Curitiba, v. 34, n. 4, p. 553-560, 2004.

CARNEIRO, C. D. R. et al. Docência e trabalhos de campo nas disciplinas Ciência do Sistema Terra I e II da UNICAMP. Revista Brasileira de Geociências, Curitiba, v. 38, n. 1, p. 130-142, 2008. 
O ciclo hidrológico como chave analítica ...

Introdução ao estudo de Ciência do Sistema Terra. Disciplina GN-102.

Ciência do Sistema Terra I, Texto-base: Roteiros de aula, orientações de estudo e leituras complementares. Campinas: IG-Unicamp, 2003. (ed. dos autores).

COBO MERINO, B.; BATANERO, C. Significado de la media en los libros de texto de secundaria. Enseñanza de las Ciencias, Barcelona, v. 22, n. 1, p. 5-18, 2004.

COMISSÃO MUNDIAL INDEPENDENTE SOBRE OS OCEANOS. O oceano... nosso futuro: relatório final. Rio de Janeiro: Interciência, 1999.

CUNHA, C. A. L. S. Geologia nos livros didáticos no Brasil: um estudo da coerência interna dos textos através do conceito de geossinclinal. 1986. 296f. Dissertação (Mestrado em Educação) - Faculdade de Educação, Universidade Estadual de Campinas, Campinas, 1986.

ECO, U. Como se faz uma tese. São Paulo: Perspectiva, 1989.

FRACALANZA, H. O que sabemos sobre livros didáticos para o ensino de ciências no Brasil. 1993. 302f. Tese (Doutorado em Educação) - Faculdade de Educação, Universidade Estadual de Campinas, Campinas. 1993.

FRACALANZA, H.; MEGID NETO, J. (Orgs.). O livro didático de ciências no Brasil. Campinas: Comedí, 2006.

GARCÍA BARROS, S.; MARTÍNEZ LOSADA, C. Análisis del trabajo práctico en textos escolares de primaria y secundaria. Enseñanza de las Ciencias, Espanha, v. 21, n.extra, p. 5-16, 2003.

GÉRARD, F.-M.; ROEGIERS, X. Conceber e avaliar manuais escolares. Porto: Porto Editora, 1998.

GONÇALVES, P. W. Indicadores da presença de conteúdos de história e filosofia da ciência em livro de texto de geologia introdutória. Ciência \& Educação, Bauru, v. 11, n. 1, p. 41-52, 2005.

GONZÁLEZ RODRÍGUEZ, C.; GARCÍA BARROS, S.; MARTÍNEZ LOSADA, C. A qué contenidos relacionados con la fotosíntesis dan más importancia los textos escolares de secundaria? Enseñanza de las Ciencias, Barcelona, v. 21, n.extra, p. 77-88, 2003.

KNAPP, B. J.; ROSS, S. R. J.; McCRAE, D. L. R. Challenge of the natural environment. Singapore: Longman Singapore, 1991. 272 p.

LOBATO, A. C. et al. Dirigindo o olhar para o efeito estufa nos livros didáticos de ensino médio: é simples entender esse fenômeno? Ensaio, Belo Horizonte, v. 11, n. 1, p. 1-18, 2009.

MARTINS, J. R. S. Plataforma continental jurídica: incorporação ao território nacional e ao ensino de geociências. 2010. 99f. Dissertação (Mestrado em Ensino e História de Ciências da Terra) - Instituto de Geociências, Universidade Estadual de Campinas, Campinas, 2010.

MEGID NETO, J. O ensino de ciências no Brasil: catálogo analítico de teses e dissertações 1972-1995. Campinas: Editora da Unicamp, 1998. 
Martins, J. R. S.; Gonçalves, P. W.; Carneiro, C. D. R.

MEGID NETO, J.; FRACALANZA, H. O livro didático de ciências: problemas e soluções. Ciência \& Educação, Bauru, v. 9, n. 2, p. 147-157, 2003.

MUÑOZ BELLO, R.; BERTOMEU SÁNCHEZ, J. R. La historia de la ciencia en los libros de texto: la(s) hipótesis de Avogadro. Enseñanza de las Ciencias, Barcelona, v. 21, n. 1, p. 147-159, 2003.

NATIONAL RESEARCH COUNCIL. National science education standards. Washington: National Academy of Sciences, 1996. Disponível em: <http:// zircon.dcsa.fct.unl.pt/dspace/bitstream/123456789/585/2/National $\% 20$ Science $\%$ 20Education\%20Standards, \%20full\%20book.pdf>. Acesso em: 22 set. 2010.

NATIONAL SCIENCE TEACHERS ASSOCIATION. NSTA position statement: the national science education standards. Arlington: NSTA, 1998. Disponível em: <http:// www.nsta.org/about/positions/standards.aspx>. Acesso em: 22 set. 2010.

PANDIELLA, S.; CALBÍ, P.; MACÊAS, A. Estrategias de recuerdo y comprensión de un texto de física. Enseñanza de las Ciencias, Barcelona, v. 21, n.extra, p. 119-129, 2003.

POTAPOVA, M. S. Geology as an historical science of nature. In: INTERACTION of sciences in the study of the Earth. Moscow: Progress, 1968. p. 117-126.

- Geologia como uma ciência histórica da Natureza. Terræ Didatica, Campinas, v. 3, n. 1, p. 86-90, 2007. Disponível em: < http://www.ige.unicamp.br/terraedidatica/v3/ pdf-v3/TD3-\%2086_91.pdf>. Acesso em: 29 abr. 2011.

QUíLEZ, J. Análisis de los errores que presentan los libros de texto universitarios de química general al tratar la energía libre de Gibbs. Enseñanza de las Ciencias, Barcelona, v. 27 , n. 3, p. 317-330, 2009.

REQUEIJO, F.; CARNEIRO, C. D. R. Zonas habitáveis na Via Láctea. Ciência Hoje, Rio de Janeiro, v. 45, n. 267, p. 38-43, 2010.

RIBEIRO, J. A. et al. Chuvas e enchentes: inovação curricular para ensinar ciclo da água. In: SIMPÓSIO DE PESQUISA EM ENSINO E HISTÓRIA DE CIÊNCIAS DA TERRA, 1. Campinas, 2007. Anais... Campinas: DGAE/IG/Unicamp, 2007. p. 233-239.

RUFATTO, C. A.; CARNEIRO, M. C. A concepção de ciência de Popper e o ensino de ciências. Ciência \& Educação, Bauru, v. 15, n. 2, p. 269-89, 2009.

SILVA, G. J.; MARTINS, C. M. C. A confiabilidade e a validação na investigação epistemológica do livro didático de Química: um desenho metodológico. Ensaio, Belo Horizonte, v. 11, n. 2, p. 1-20. 2009.

STYLIANIDOU, F.; ORMEROD, F.; OGBORN, J. Analysis of science textbook pictures about energy and pupils' readings of them. International Journal of Science Education, Londres, v. 24, n. 3, p. 257-283, 2002.

Artigo recebido em setembro de 2010 e aceito em março de 2011. 